\title{
Knowledge and Awareness of Authorship Practices Among Health Science Students: A Cross-Sectional Study
}

\author{
Hisham Badreldin' \\ Saud Aloqayli ${ }^{\text {I }}$ \\ Reem Alqarni ' \\ Hayaa Alyahya' \\ Abdulmajeed Alshehri ${ }^{1}$ \\ Mohammed Alzahrani' \\ Amjad Al Tawalbeh (D) ${ }^{2}$ \\ Wesam W Ismail (D ${ }^{3}$ \\ 'Department of Pharmacy Practice, \\ College of Pharmacy, King Saud Bin \\ Abdulaziz University for Health Sciences, \\ King Abdullah International Medical \\ Research Center, Department of \\ Pharmaceutical Care Services, King \\ Abdulaziz Medical City, Riyadh, Saudi \\ Arabia; ${ }^{2}$ Faculty of Pharmacy, Jordan \\ University of Science and Technology, Ar- \\ Ramtha, Jordan; ${ }^{3}$ Pharmacy Practice and \\ Science Department, College of \\ Pharmacy, University of lowa, lowa City, \\ IA, USA
}

Background: The International Committee of Medical Journal Editors has published clear guidelines on the authorship of scientific papers. It is the research team's responsibility to review and ensure those guidelines are met. Authorship ethics and practices have been examined among healthcare professionals or among particular health science students such as medical students. However, there is limited evidence to assess the knowledge of authorship roles and practices among health science students.

Methods: We conducted a cross-sectional study to assess the knowledge of authorship guidelines practices among health science students at King Saud bin Abdulaziz University for Health Sciences in Riyadh, Saudi Arabia. A survey was developed and distributed. It covered several domains, including demographic characteristics, participant's knowledge and attitude of authorship practices, knowledge and experience with ghost and guest authorships, and knowledge of institutional authorship policies. Moreover, a score was computed to reflect the respondents' knowledge about authorship practices.

Results: Among the 321 participants who agreed to take the survey, two-thirds agreed with and supported that multi-authored articles' credit allocation should be based on the most significant contribution and contributions to the manuscript writing. Almost $47 \%$ agreed that team relationships would influence authorship allocation. The majority of the participants were not aware of their institutional research and publication policies. Also, around $50 \%$ of participants were not aware of guest or ghost authorships. Finally, the knowledge score about authorship credits, allocation, contribution, order, and guidelines was higher among students who were assigned as corresponding authors and those who were aware of their institutional authorship guidelines and policies.

Conclusion: In conclusion, our findings suggest that health science students may have limited knowledge about authorship guidelines and unethical behaviors involved in a scientific publication. Universities and research centers should make more efforts to raise the awareness of health science students regarding authorship guidelines while ensuring that they comply with those guidelines.

Keywords: education, knowledge, ethics, research article, publications

\section{Introduction}

Authorship in the research field has several definitions, yet most of these definitions agree that the author is the one with significant contributions to the published research. Authorship belongs not only to the actual writers but also to the individuals who made substantial contributions and held significant responsibility for the data, concepts, and interpretation of results for a published work. ${ }^{1}$ Those who do
Correspondence: Hisham Badreldin College of Pharmacy, King Saud Bin Abdulaziz University for Health Sciences, PO Box 3660, Riyadh, II48I, Saudi Arabia

Email aldeenh@ksau-hs.edu.sa 
not meet these criteria should be acknowledged. For the most part, the first author is the individual who made the greatest contribution to the work, while the corresponding author is the person who assumes primary responsibility for communicating with the journal staff during the submission of manuscripts and peer review and generally ensures that all requirements of the journal and the publisher are properly met. The order of the authors shall be determined by the consensus among the co-authors. ${ }^{2}$

In the extremely competitive world of scholarly activities, authorship-related issues are increasing. Not crediting authors for their work, disagreements between collaborators, or assigning noncontributing persons as authors are among the most common issues. Ghost and guest authorships are also common authorship malpractices. ${ }^{3}$ A ghost author is one who participates in discussions and provides ideas in research but is not listed as an author in the final publication. ${ }^{1}$ An honorary author is one who does not meet the criteria for inclusion in the authorship list but is named as an author. ${ }^{4}$

To reduce these unethical authorship practices, different groups, such as the Committee on Publication Ethics (COPE) and the International Committee of Medical Journal Editors (ICMJE), have created and published many guidelines. ${ }^{5,6}$ The ICMJE's recommendations are mostly adopted in the biomedical field and implemented by almost all peer-reviewed journals. Usually, these recommendations are published on journal websites. Authors must prove commitment to these recommendations upon submitting their manuscripts. ${ }^{6}$

According to ICMJE definitions, authors must meet four criteria to be listed in the authorship line:

1. They should contribute intellectually to the research concept or design.

2. They should significantly contribute to the review process of the paper.

3. They should provide the final approval of the paper before the submission process.

4. They should take public responsibility for all aspects of the research.

In case an individual does not meet these criteria, they could be listed in the acknowledgments section. Over the past few decades, publishing research has played fundamental roles for scientists and healthcare professionals across all scholarly disciplines. The importance of writing research papers could be categorized into social and economic benefits. Gaining a reputation and recognition by peers or experts in the field is one of the social aspects of publishing papers. Furthermore, on a personal level, publishing research is considered an individual achievement in terms of advancing knowledge in this particular field. Moreover, research is used as an evaluation tool for promotion in academic institutions. ${ }^{7}$

The case is different when it comes to health science students. Depending on the surrounding environment, health science students may engage in research for several reasons, such as fulfilling the school's graduation requirements and building strong Curriculum Vitae to compete on residency seats. Others may engage voluntarily in research projects in order to stimulate their research interest. Previous evidence focused primarily on the influence of students' characteristics on voluntary engagement in scientific research and examining the rate of publication after graduation in those who engaged in undergraduate extracurricular research activities. ${ }^{8,9}$

To the best of our knowledge, there is a lack of studies that explored the knowledge of health science students regarding the authorship guidelines and practices. For this reason, we conducted this study to examine the knowledge of health science students at the King Saud bin Abdulaziz University for Health Sciences (KSAU-HS) regarding authorship guidelines and practices.

\section{Methods}

\section{Study Design}

We conducted a cross-sectional study at KSAU-HS in Riyadh, Saudi Arabia. We included students from different academic years enrolled in different health science colleges, including medicine (COM), pharmacy (COP), dentistry (COD), nursing (CON), and applied medical sciences (COAMS). No sampling technique was used, as all students were asked to fill out an online selfadministered questionnaire. For the sample selection approach, a non-probabilistic method, including purposive and convenience sampling techniques, was employed. A survey was distributed between March and December 2019. All survey answers were collected anonymously without identification information. The study protocol and survey were reviewed and approved by the institutional review board at King Abdullah International Medical Research Center (KAIMRC) in Riyadh, Saudi Arabia. All students were asked to signify their agreement on a consent form before taking the survey. 


\section{Survey Development}

The survey was developed to evaluate the knowledge of KSAU-HS students about authorship and its malpractices. The questionnaire was derived from several previously published surveys and modified to fit the scope of this study. ${ }^{10-12}$ Since health science students at KSAU-HS are taught using the English language, the language of the survey was not translated into Arabic. The survey consisted of four main domains and subdomains. The first domain was intended to collect the specific demographic characteristics of participants. The second domain was intended to assess the participants' attitudes regarding authorship practices. The third domain was intended to examine the participants' knowledge and experience with ghost and guest authorships. The fourth domain was intended to assess the participants' knowledge of their institutional authorship policies.

\section{Statistical Analysis}

We used descriptive statistics to analyze the data. Continuous variables were summarized using mean \pm SD and median (IQR, interquartile range), and proportions were used for categorical variables. A continuous knowledge score (KS) was constructed from seven questions that mainly reflected respondents' knowledge about authorship credits, allocation, contribution, order, and guidelines. The questionnaire considers the respondents' gender, college, and research experience (maximum score $=35$; higher scores reflect higher knowledge). A logistic regression model was used to examine the association between the $\mathrm{KS}$ as the dependent variable and other parameters as independent variables. The collected data were compiled using Microsoft Excel 2010 (Office 365, Microsoft Ltd., USA) and analyzed using Statistical Package for Social Sciences 20.0 version (SPSS Inc. Chicago, USA).

\section{Results}

\section{Demographic Characteristics of Participants}

As shown in Table 1, the total number of students who agreed to participate in this study was 321 . Close to $50 \%$ were female. The majority of the respondents were in their first three academic years and came from the COM, COP, and COD colleges-29.3\%, 28.0\%, and $34.0 \%$, respectively. There were participants as well from the $\mathrm{CON}$ and the COAMS $-3.7 \%$ and $4.0 \%$, respectively.
Table I Demographic Characteristics of Participants N=32 I

\begin{tabular}{|c|c|c|c|}
\hline \multicolumn{4}{|l|}{ Variables } \\
\hline \multicolumn{3}{|l|}{ Gender, n (\%) } & \\
\hline \multicolumn{3}{|l|}{ Male } & I $56(48.2 \%)$ \\
\hline \multicolumn{3}{|l|}{ Female } & $165(51.4 \%)$ \\
\hline \multicolumn{2}{|l|}{ College, n (\%) } & \multicolumn{2}{|c|}{ Academic year, n (\%) } \\
\hline \multirow[t]{4}{*}{ College of Medicine } & 94 (29.3\%) & First year & II (3.4\%) \\
\hline & & Second year & $74(23.1 \%)$ \\
\hline & & Third year & $0(0 \%)$ \\
\hline & & Fourth year & $9(2.8 \%)$ \\
\hline \multirow[t]{4}{*}{ College of Pharmacy } & $93(29.0 \%)$ & First year & $20(6.2 \%)$ \\
\hline & & Second year & $32(10.0 \%)$ \\
\hline & & Third year & $38(11.8 \%)$ \\
\hline & & Fourth year & $3(0.9 \%)$ \\
\hline \multirow[t]{4}{*}{ College of Dentistry } & $109(34.0 \%)$ & First year & $56(17.4 \%)$ \\
\hline & & Second year & $15(4.7 \%)$ \\
\hline & & Third year & 19 (5.9\%) \\
\hline & & Fourth year & $19(5.9 \%)$ \\
\hline \multirow[t]{3}{*}{ College of Nursing } & $12(3.7 \%)$ & First year & $2(0.6 \%)$ \\
\hline & & Second year & $0(0 \%)$ \\
\hline & & Third year & $10(3.1 \%)$ \\
\hline \multirow{4}{*}{$\begin{array}{l}\text { College of Applied } \\
\text { Medical Sciences }\end{array}$} & $13(4.0 \%)$ & First year & $3(0.9 \%)$ \\
\hline & & Second year & $6(1.9 \%)$ \\
\hline & & Third year & $4(1.2 \%)$ \\
\hline & & Fourth year & $0(0 \%)$ \\
\hline \multicolumn{3}{|c|}{ Number of publications, $\mathrm{n}$ (\%) } & \\
\hline \multicolumn{3}{|l|}{0} & $282(87.9 \%)$ \\
\hline \multicolumn{3}{|l|}{$\mathrm{I}-2$} & $20(6.2 \%)$ \\
\hline \multicolumn{3}{|l|}{$3-4$} & $10(3.1 \%)$ \\
\hline \multicolumn{3}{|l|}{ More than 4} & $9(2.8 \%)$ \\
\hline \multicolumn{3}{|c|}{ Number of completed research projects, n (\%) } & \\
\hline \multicolumn{3}{|l|}{0} & $210(65.4 \%)$ \\
\hline \multicolumn{3}{|l|}{$1-2$} & $82(25.5 \%)$ \\
\hline \multicolumn{3}{|l|}{$3-4$} & $6(1.9 \%)$ \\
\hline \multicolumn{3}{|l|}{ More than 4} & $23(7.2 \%)$ \\
\hline \multicolumn{4}{|c|}{$\begin{array}{l}\text { Number of research projects with less than } 4 \text { authors, } \\
n(\%)\end{array}$} \\
\hline \multicolumn{3}{|l|}{0} & $261(81.6 \%)$ \\
\hline \multicolumn{3}{|l|}{$1-2$} & $49(15.3 \%)$ \\
\hline \multicolumn{3}{|l|}{$3-4$} & $10(3.1 \%)$ \\
\hline More than 4 & & & $0(0 \%)$ \\
\hline $\begin{array}{l}\text { Number of research pr } \\
\mathrm{n}(\%)\end{array}$ & ts with more $t$ & an 4 authors, & \\
\hline 0 & & & $166(52.4 \%)$ \\
\hline $\mathrm{I}-2$ & & & $133(42.0 \%)$ \\
\hline $3-4$ & & & $10(3.2 \%)$ \\
\hline More than 4 & & & $8(2.4 \%)$ \\
\hline
\end{tabular}

(Continued) 
Table I (Continued).

\begin{tabular}{|l|c|}
\hline \multicolumn{2}{|l|}{ Variables } \\
\hline $\begin{array}{l}\text { Have you been an author of/on a multi-authored } \\
\text { paper, } \mathrm{n}(\%) \\
\text { Yes }\end{array}$ & $132(41.3 \%)$ \\
No & $188(58.7 \%)$ \\
\hline $\begin{array}{l}\text { Have you been first author, } \mathrm{n}(\%) \\
\text { Yes }\end{array}$ & $11(3.4 \%)$ \\
No & $310(96.6 \%)$ \\
\hline $\begin{array}{l}\text { Have you been a corresponding author, } \mathrm{n}(\%) \\
\text { Yes }\end{array}$ & $104(32.5 \%)$ \\
No & $216(67.5 \%)$ \\
\hline Source of information regarding authorship guideline, & \\
$\mathrm{n}$ (\%) & $193(60.1 \%)$ \\
Lectures & $20(6.3 \%)$ \\
Workshop & $29(9.0 \%)$ \\
Experience & $60(18.7 \%)$ \\
Self-reading & $19(5.9 \%)$ \\
Other &
\end{tabular}

The percentage of respondents who participated in previous research and have completed at least one publication was $12.1 \%$. Around $47 \%$ of the respondents participated in research projects with more than four authors. However, close to $18 \%$ of them were part of research projects with less than four authors. Close to $68 \%$ of the respondents have been assigned as corresponding authors previously, and almost $60 \%$ of the respondents obtained information regarding authorship guidelines from didactic lectures.

\section{Participant's Attitude Regarding Authorship Practices}

As shown in Table 2, when participants were asked if they agree that the authorship listing and order were discussed at the beginning of a new collaboration, only $9 \%$ expressed their disagreement, $16.5 \%$ were neutral, and $16 \%$ were unsure, leaving over half of the responses within the agreement domain. The survey offered four approaches to allocate credit to multi-authored articles:

1. Authors' order and credit should be allocated according to the contributions to the project in the following order: greatest contribution first.

2. Authors' order and credit should be allocated according to the contributions to the manuscript writing in the following order: greatest contribution first.

3. Authors' order and credit should be allocated according to the contributions to the project in the following order: least contribution first.

4. Authors' order and credit should be allocated according to one's needs (promotion, application for a position, etc.).

Approximately $60 \%$ of the respondents agreed with and supported the first two mentioned approaches. It is worth mentioning that the difference between agreeing and strongly disagreeing is significant only in these two statements. On the other hand, a small minority supported the later mentioned two methods (11\% either strongly agreed or agreed that the authors with the least contributions should be mentioned first, and $22 \%$ either strongly agreed or agreed that the order should be allocated according to one's needs).

When it comes to the complexity of establishing definitive criteria for authorship of a research article, approximately $40 \%$ strongly agreed or agreed on the difficulty of tailoring such definitive criteria. When 152 (47.4\%) subjects agreed/strongly agreed with the statement that the team's relationships would influence authorship allocation, only $50(15.7 \%)$ participants disagreed/strongly disagreed. In response to the ninth statement, at your institution, allocating authorship credit is done by following specific authorship guidelines; close to one-third of those surveyed agreed/strongly agreed to the statement. Close to $50 \%$ of the respondents either strongly agreed or agreed with acknowledging individuals who contributed to the work but were not qualified to be listed as authors. Over half of those surveyed agreed that students might be forced to include their mentors as authors as mentors.

\section{Participant's Knowledge Regarding Authorship List and Public Responsibility}

As shown in Table 3, most of the students (72.1\%) agreed that the owner of the research idea should be listed as an author in manuscripts even without a substantial contribution to the work. Regarding the research and lab technicians and the funding provider, a large proportion of the participants, up to one-third of the respondents, were not sure if they should be listed as authors of a manuscript $(29.7 \%$ and $24.5 \%)$ and another third $(34.4 \%$ and $40.9 \%)$ were in favor of listing the 
Table 2 Frequency Distribution of the Participant's Experiences and Attitude Regarding Authorship Practices

\begin{tabular}{|c|c|c|c|c|c|c|c|}
\hline \multicolumn{8}{|l|}{ In my Experience } \\
\hline & $\begin{array}{l}\text { Strongly } \\
\text { Agree }\end{array}$ & Agree & Neutral & Disagree & $\begin{array}{l}\text { Strongly } \\
\text { Disagree }\end{array}$ & $\begin{array}{l}\text { Do not } \\
\text { Know }\end{array}$ & Total \\
\hline $\begin{array}{l}\text { Authorship listing and order are usually discussed } \\
\text { at the beginning of a new collaboration }\end{array}$ & 78 (24.3\%) & 110 (34.3\%) & $53(16.5 \%)$ & II (3.4\%) & $18(5.6 \%)$ & 51 (I5.9\%) & 321 \\
\hline $\begin{array}{l}\text { Authors' order and credit should be allocated } \\
\text { according to the contributions to the project in } \\
\text { the following order: greatest contribution first }\end{array}$ & $100(31.2 \%)$ & 99 (30.8\%) & 35 (10.9\%) & $0(0 \%)$ & $0(0 \%)$ & 87 (27.1\%) & 321 \\
\hline $\begin{array}{l}\text { Authors' order and credit should be allocated } \\
\text { according to the contributions to the manuscript } \\
\text { writing in the following order: greatest } \\
\text { contribution first }\end{array}$ & $96(30.0 \%)$ & 109 (34.0\%) & $53(16.6 \%)$ & $5(1.6 \%)$ & $2(0.6 \%)$ & $55(17.2 \%)$ & 320 \\
\hline $\begin{array}{l}\text { Authors' order and credit should be allocated } \\
\text { according to the contributions to the project in } \\
\text { the following order: least contribution first }\end{array}$ & $6(1.9 \%)$ & 35 (10.9\%) & $50(15.6 \%)$ & $83(25.9 \%)$ & 110 (34.3\%) & 37 (I I.5\%) & 321 \\
\hline $\begin{array}{l}\text { Authors' order and credit should be allocated } \\
\text { according to one's needs (promotion, application } \\
\text { for position, etc.) }\end{array}$ & $18(5.6 \%)$ & $53(16.5 \%)$ & 97 (30.2\%) & 70 (21.8\%) & $34(10.6 \%)$ & $49(15.3 \%)$ & 321 \\
\hline $\begin{array}{l}\text { It is difficult to establish definitive criteria for } \\
\text { authorship of research article }\end{array}$ & $36(11.2 \%)$ & 89 (27.7\%) & 91 (28.3\%) & 43 (13.4\%) & 14 (4.4\%) & $48(15.0 \%)$ & 321 \\
\hline $\begin{array}{l}\text { Journals should always mention the contribution } \\
\text { of each author }\end{array}$ & 57 (17.7\%) & $124(38.6 \%)$ & $83(25.9 \%)$ & $25(7.8 \%)$ & I (0.3\%) & $31(9.7 \%)$ & 321 \\
\hline $\begin{array}{l}\text { Allocating authorship is influenced by the team's } \\
\text { relationships }\end{array}$ & $53(16.5 \%)$ & 99 (30.9\%) & 81 (25.3\%) & 37 (II.6\%) & $13(4.1 \%)$ & 37 (I I.6\%) & 320 \\
\hline $\begin{array}{l}\text { At your institution, allocating authorship credit is } \\
\text { done through following specific authorship } \\
\text { guidelines }\end{array}$ & $23(7.2 \%)$ & $76(23.7 \%)$ & $98(30.5 \%)$ & $20(6.2 \%)$ & $22(6.9 \%)$ & $82(25.5 \%)$ & 321 \\
\hline $\begin{array}{l}\text { Persons who contributed to the work but were } \\
\text { not qualified to be authors should be } \\
\text { acknowledged }\end{array}$ & $102(31.8 \%)$ & $84(26.1 \%)$ & 77 (24.0\%) & 14 (4.4\%) & $2(0.6 \%)$ & $42(13.1 \%)$ & 321 \\
\hline $\begin{array}{l}\text { Students may be forced to include their } \\
\text { supervisors (mentors) as authors }\end{array}$ & $55(17.1 \%)$ & III (34.6\%) & $69(21.5 \%)$ & $4 \mathrm{I}(12.8 \%)$ & II (3.4\%) & $34(10.6 \%)$ & 321 \\
\hline
\end{tabular}

name in the acknowledgments section. Regarding the roles of biostatistician and manuscript technical writer, the percentages were very close as $29.6 \%$ and $28.0 \%$ agreed that these individuals needed to be added as authors. However, $32.1 \%$ and $28.3 \%$ said these people needed to be added in the acknowledgment part, respectively. Close to $35 \%$ of the respondents stated that all authors should take public responsibility for the published work.

\section{Guest and Ghost Authorships}

As shown in Table 4, approximately more than half $(63.6 \%$, $65.4 \%$, respectively) of the respondents were unaware of guest or ghost authorship before this time. A large percentage of participants $(82.6 \%, 85.0 \%)$ said that guest or ghost authoring was not granted in any manuscript/project in which they were authors. Around $17.0 \%$ and $11 \%$ of the respondents were influenced to include or remove authors from their manuscripts before being sent to publications, respectively. Approximately 
Table 3 Frequency Distribution of the Participant's Knowledge Regarding Authorship List and Public Responsibility

\begin{tabular}{|c|c|c|c|c|c|c|}
\hline $\begin{array}{l}\text { The Following Persons Should be Listed as Authors } \\
\text { of a Manuscript Even Without Substantial } \\
\text { Contribution to the Work }\end{array}$ & Yes & No & Not Sure & \multicolumn{2}{|c|}{ Acknowledged } & Total \\
\hline The owner of research idea & $230(72.1 \%)$ & $18(5.6 \%)$ & 38 (11.9\%) & \multicolumn{2}{|c|}{$33(10.3 \%)$} & 319 \\
\hline Research or lab technician & $51(15.9 \%)$ & $64(20.0 \%)$ & $95(29.7 \%)$ & \multicolumn{2}{|c|}{$110(34.4 \%)$} & 320 \\
\hline The funding provider & $64(20.1 \%)$ & 46 (I4.5\%) & 78 (24.5\%) & \multicolumn{2}{|c|}{130 (40.9\%) } & 318 \\
\hline The biostatistician & $95(29.6 \%)$ & $50(15.6 \%)$ & $73(22.7 \%)$ & \multicolumn{2}{|c|}{$103(32.1 \%)$} & 321 \\
\hline The manuscript technical writer (unpaid service) & $90(28.0 \%)$ & $35(10.9 \%)$ & $105(32.7 \%)$ & \multicolumn{2}{|c|}{$9 \mathrm{l}(28.3 \%)$} & 321 \\
\hline The owner of the lab & $30(9.3 \%)$ & $118(36.8 \%)$ & $90(28.0 \%)$ & \multicolumn{2}{|c|}{$83(25.9 \%)$} & 321 \\
\hline The department head (supervisor) & $68(21.2 \%)$ & III (34.6\%) & $86(26.8 \%)$ & \multicolumn{2}{|c|}{$56(17.4 \%)$} & 321 \\
\hline Data collectors (students) & $|4|(43.9 \%)$ & II (3.4\%) & $67(20.9 \%)$ & \multicolumn{2}{|c|}{$102(31.8 \%)$} & 321 \\
\hline The provider of materials, reagents or patients for the & $56(17.5 \%)$ & $72(22.5 \%)$ & $106(33.1 \%)$ & \multicolumn{2}{|c|}{$86(26.9 \%)$} & 320 \\
\hline & $\begin{array}{c}\text { First } \\
\text { Author }\end{array}$ & $\begin{array}{c}\text { Corresponding } \\
\text { Author }\end{array}$ & $\begin{array}{l}\text { Research } \\
\text { Team Head }\end{array}$ & All Authors & $\begin{array}{l}\text { Do not } \\
\text { Know }\end{array}$ & \\
\hline Author who should take public responsibility for the work is & $93(29.1 \%)$ & $21(6.5 \%)$ & $22(6.9 \%)$ & $116(36.3 \%)$ & $68(21.3 \%)$ & 320 \\
\hline
\end{tabular}

Table 4 Frequency Distribution of the Participant's Knowledge and Experience of Ghost and Guest Authors and Authorship Malpractices

\begin{tabular}{|c|c|c|c|}
\hline & Yes & No & Total \\
\hline Were you aware of Guest authorship before this time? & $117(36.4 \%)$ & $204(63.6 \%)$ & 321 \\
\hline Were you aware of Ghost authorship before this time? & III (34.6\%) & $210(65.4 \%)$ & 321 \\
\hline Has guest authorship been awarded in any manuscript/project on which you were an author? & $56(17.4 \%)$ & $265(82.6 \%)$ & 321 \\
\hline Has ghost authorship been awarded in any manuscript/project on which you were an author? & $48(15.0 \%)$ & $272(85.0 \%)$ & 320 \\
\hline Have you been influenced by anyone to include them as an author in your work? & $54(17.1 \%)$ & $262(82.9 \%)$ & 316 \\
\hline Have you been influenced by anyone to remove persons as an author from your work? & $35(10.9 \%)$ & $286(89.1 \%)$ & 321 \\
\hline Have you been involved in a dispute with your colleagues about the order of authorship? & $77(24.1 \%)$ & $243(75.9 \%)$ & 320 \\
\hline Do you think relationships could adversely affect or directly influence the process of assigning authors? & $206(64.4 \%)$ & $114(35.6 \%)$ & 320 \\
\hline $\begin{array}{l}\text { Do you think courses or workshops should be provided for all students to ensure obtaining a proper } \\
\text { background about research ethics that would help in protecting authors' right and minimizing research } \\
\text { malpractice in general? }\end{array}$ & $211(65.9 \%)$ & $109(34.1 \%)$ & 320 \\
\hline
\end{tabular}

$24 \%$ entered into a dispute about the order of authorship. Close to $66 \%$ of the respondents agreed that courses and workshops should be provided for all students to ensure that they obtained a proper background in research ethics.

\section{Participants' Knowledge Regarding Institutional Authorship Policy}

As shown in Table 5, close to $70 \%$ of the respondents were not aware of their institutional research and publication policies. Thus, they did not know if the policy defined gift authorship or the authors' criteria and listing order.

\section{Knowledge Score}

As shown in Table 6, a continuous knowledge score (KS) was constructed from seven questions that mainly reflect the respondent's knowledge about authorship credits, allocation, contribution, order, and guidelines. The standardized Cronbach's Coefficient Alpha of the score was 
Table 5 Frequency Distribution of the Participant's Knowledge Regarding Authorship Institutional Policy

\begin{tabular}{|c|c|c|c|c|c|}
\hline & Yes & No & Not Sure & $\begin{array}{l}\text { Do not } \\
\text { Know }\end{array}$ & Total \\
\hline $\begin{array}{l}\text { Are you aware about your institution research authorship and publication } \\
\text { conduct policy? }\end{array}$ & $29(9.0 \%)$ & $222(69.2 \%)$ & $4 \mathrm{I}(12.8 \%)$ & $29(9.0 \%)$ & 321 \\
\hline \multicolumn{6}{|l|}{ If Yes } \\
\hline Is gift authorship clearly defined in your institution authorship policy? & $19(5.9 \%)$ & $33(10.3 \%)$ & $5517.2 \%)$ & $213(66.6 \%)$ & 320 \\
\hline $\begin{array}{l}\text { According to your institution authorship policy, the order of authors depends } \\
\text { on contribution to the manuscript }\end{array}$ & $26(8.1 \%)$ & $3310.3 \%$ & $4514.1 \%$ & $21667.5 \%$ & 320 \\
\hline $\begin{array}{l}\text { According to your institution authorship policy, providing funding, administrative } \\
\text { or technical advice or patient's data is a qualification for authorship }\end{array}$ & $22(6.9 \%)$ & $30(9.4 \%)$ & $56(17.4 \%)$ & $212(66.3 \%)$ & 320 \\
\hline $\begin{array}{l}\text { According to your institution authorship policy, It is the responsibility of the } \\
\text { primary investigator to define the authorship list and its order }\end{array}$ & $35(10.9 \%)$ & $22(6.9 \%)$ & $49(15.2 \%)$ & $215(67.0 \%)$ & 321 \\
\hline
\end{tabular}

Table 6 Knowledge Score

\begin{tabular}{|c|c|c|c|}
\hline Variables & Coefficient & Standard Error & 95\% Confidence Interval \\
\hline Female & -0.732 & 0.86 & $-2.417-0.952$ \\
\hline \multicolumn{4}{|l|}{ College $\S^{\S}$} \\
\hline College of Dentistry & -0.410 & 2.23 & $-4.798-3.979$ \\
\hline College of Medicine & -0.545 & 2.45 & $-5.375-4.285$ \\
\hline College of Nursing & $2.44 I$ & 3.13 & $-3.7 \mid 4-8.597$ \\
\hline College of Pharmacy & 0.804 & 2.29 & $-3.699-5.306$ \\
\hline Academic year & 0.253 & 0.51 & $-0.753-1.260$ \\
\hline Having a project published & -0.376 & 1.55 & $-3.426-2.674$ \\
\hline Having a completed project & 1.770 & 1.09 & $-0.380-3.920$ \\
\hline Being first author & -0.748 & 2.49 & $-5.654-4.158$ \\
\hline Being corresponding author & $4.859 * * *$ & 1.31 & $2.280-7.438$ \\
\hline Aware of institutional authorship guidelines & $2.230^{*}$ & 1.09 & $0.086-4.374$ \\
\hline Constant & $19.690 * * *$ & 2.32 & $15.133-2.247$ \\
\hline
\end{tabular}

Notes: ${ }^{*} p<0.05 . * * * p<0.001 .{ }^{\circledR}$ College of Applied Medical Sciences as the reference category.

0.81. The mean score (STD) was 22.5 (7.8), with a max score of 35 . Higher scores reflect higher knowledge. Our results showed that students who were assigned as corresponding authors had statistically significant higher KSs by 4.9 points than those who were not assigned as corresponding authors. Also, students who were aware of the institutional authorship guidelines had significantly higher KSs, by 2.2 points.

\section{Discussion}

This study aimed to assess the knowledge of KSAU-HS health science students about authorship guidelines and practices. To the best of our knowledge, this is the first study to assess the authorship practices among health science students. Previous studies in this field mainly assessed this matter among faculty members or among particular health science students such as medical students. For example, in a comparative study that included medical and pharmacy faculty members, which included 54 and 41 individuals, respectively, the authors reported that pharmacy faculty had a better and clearer idea about authorship ethics than medical faculty. When they were asked regarding the ICMJE guidelines, only $22.2 \%$ of the medical faculty and $39 \%$ of the pharmacy faculty knew these guidelines. Gift authorship was prevalent in more than $80 \%$ of the medical faculty and $29 \%$ of the pharmacy faculty. ${ }^{13}$ In another study that used a national survey to assess the medical student experience with authorship, the 
investigators found that two-thirds of the medical students never received formal training in authorship guidelines previously. ${ }^{14}$ Moreover, close to $25 \%$ of the respondents indicated that the criteria for authorship were never clarified to them. ${ }^{14}$ Our findings showed that most of the included sample of health science students agreed that the author's order should be allocated according to the contributions to the project or manuscript writing, and those with the greatest contributions should be listed first, which is the most common practice.

There was a lack of knowledge and understanding regarding the authorship list and public responsibility among participants. Our results showed a large percentage of the respondents believed that data collectors and the owner of the research idea would qualify these individuals to be authors, which contradicts with the ICMJE criteria that should be met before being listed as an author. When asked about public responsibility, only $36.3 \%$ reported that all authors should take it to be listed as an author. Many factors could explain this gross lack of knowledge and misunderstanding. First, the percentages of students who have no publications or projects are $87.9 \%$ and $65.4 \%$, respectively. Second, the majority of the students were not aware of their institution's authorship guidelines. Potential solutions to address this issue include integrating the institution's guidelines into the curriculum, involving students in research from the first year of the professional program, and conducting workshops for the students to enhance their research skills and ethics. The lack of awareness of institutional guidelines may not be limited to students only but may include faculty members, notably after reporting the lack of knowledge of authorship guidelines among medical and pharmacy faculty members in a study conducted in India9. It is also important to raise faculty awareness regarding authorship ethics and practices and encourage them to discuss these ethics and practices with their students.

More than half of the participants were not aware of guest or ghost authorships, and around $17.4 \%$ and $15.0 \%$ of the participants reported that guest or ghost authoring was granted in at least one of their projects. A previous study suggested that the prevalence of honorary and ghost authorship in medical journals is close to $20 \%$ and $11 \%$, respectively. ${ }^{15}$ As science and healthcare practice must be based on honesty and trust, more efforts are needed to increase their knowledge and awareness about ghost and guest authorship, which can sometimes be used to boost research quality. Ghost and guest authorships may compromise the validity and integrity of any research. ${ }^{16}$ To minimize that, some solutions can be implemented, such as integrating research ethics within the curricula and providing courses and workshops for all students and researchers, notably after identifying that $65.9 \%$ of the participants are willing to obtain courses and workshops on research ethics.

Universities and research centers have an important role in implementing authorship institutional policy and guidelines. More stringent guidelines may prevent unethical research malpractice. One study showed significant improvement in medical schools that implemented stringent guidelines that forbid ghost authorship. ${ }^{17}$ Therefore, frequent assessment of institutional authorship policy is required to ensure improvement in the quality of research. Surprisingly, our findings showed that $69 \%$ of students were not aware of the institution's research authorship and publication conduct policy, which creates another obstacle. This could be minimized by exposing students to the institutional guidelines and implementing a standardized strategy that protects authors' rights and minimizes unethical practices.

The KS was higher among students who were corresponding authors before or were aware of institutional authorship guidelines. This reflects the importance of exposing students to journals and institutional guidelines. Since corresponding authors have to read the journal's requirements and authorship guidelines, this would explain their higher KS. It highlights the importance of exposing students to the institution's authorship guidelines to build their knowledge and ethical practices.

Our study has several strengths. First, to the best of our knowledge, it is the first study to assess knowledge about authorship guidelines from students' perspectives. Second, it included students from different healthcare specialties and compared their knowledge scores. Additionally, our findings emphasized the importance of implementing a standardized strategy to improve research quality and minimize research malpractice at institutional and faculty levels, notably after identifying many variations in attitudes and gaps in knowledge and understanding research ethics and authorship guidelines among students.

Our study has several limitations. First, most participants were in their first three years of the professional programs and had no publications or completed research projects. Second, our study is at risk of selection bias, which is associated with the online survey. Finally, our results may not be extrapolated to last year's students, given the small number of participants representing that group. However, we believe that this study is one of the few that assessed the attitudes and knowledge of health science students about authorship guidelines, and the results of this study will be utilized to increase students' knowledge and awareness of research ethics and authorship guidelines at the institutional, faculty, and student levels. 


\section{Conclusion}

In conclusion, our findings revealed that health science students may have limited knowledge about authorship guidelines and unethical behaviors involved in scientific publications. Universities and research centers should make more efforts to ensure a clear understanding of and compliance with authorship guidelines among health science students.

\section{Data Sharing Statement}

The authors declare that they had full access to all of the data in this study, and the authors take complete responsibility for the integrity of the data and the accuracy of the data analysis. Data used to support the findings of this study are available from the corresponding author upon request.

\section{Ethics Approval and Consent to Participate}

Ethical approval has been obtained from the Institutional Review Board at King Abdullah International Medical Research Center. Prior to completing surveys, respondents provided informed consent electronically.

\section{Author Contributions}

All authors made substantial contributions to conception and design, acquisition of data, or analysis and interpretation of data; took part in drafting the article or revising it critically for important intellectual content; agreed to submit to the current journal; gave final approval of the version to be published; and agree to be accountable for all aspects of the work.

\section{Funding}

The authors received no financial support for the research, authorship, or publication of this article.

\section{Disclosure}

The authors declared no potential conflicts of interest for this work or with respect to the research, authorship, and/ or publication of this article.

\section{References}

1. Song SY. What are the principles for assigning authorship? Arch Plast Surg. 2017:44(1):3-4. doi:10.5999/aps.2017.44.1.3

2. Bhopal RS, Rankin JM, McColl E, et al. Team approach to assigning authorship order is recommended. BMJ. 1997;314(7086):1046-1047.

3. Kornhaber RA, McLean LM, Baber RJ. Ongoing ethical issues concerning authorship in biomedical journals: an integrative review. Int J Nanomedicine. 2015;10:4837-4846. doi:10.2147/IJN.S87585

4. Wislar JS, Flanagin A, Fontanarosa PB, Deangelis CD. Honorary and ghost authorship in high impact biomedical journals: a cross sectional survey. BMJ. 2011;343(1):d6128. doi:10.1136/bmj.d6128

5. Committee on Publication Ethics. Committee on Publication Ethics (COPE). Guidelines on good publication practice. J Postgrad Med. 2000;46(3):217-221.

6. International Committee of Medical Journal Editors (ICMJE). Uniform requirements for manuscripts submitted to biomedical journals: writing and editing for biomedical publication. Haematologica. 2004;89(3):264.

7. Peh W. Scientific writing and publishing: its importance to radiologists. Biomed Imaging Interv J. 2007;3(3):e55. doi:10.2349/ biij.3.3.e55

8. Salgueira A, Costa P, Goncalves M, Magalhaes E, Costa MJ Individual characteristics and student's engagement in scientific research: a cross-sectional study. BMC Med Educ. 2012;12(1):95. doi:10.1186/1472-6920-12-95

9. Reinders JJ, Kropmans TJ, Cohen-Schotanus J. Extracurricular research experience of medical students and their scientific output after graduation. Med Edu. 2005;39(2):237. doi:10.1111/j.1365-2929. 2004.02078.x

10. Alshogran OY, Al-Delaimy WK. Understanding of international committee of medical journal editors authorship criteria among faculty members of pharmacy and other health sciences in Jordan. J Empir Res Hum Res Ethics. 2018;13(3):276-284. doi:10.1177/1556 264618764575

11. Mitcheson H, Collings S, Siebers RW. Authorship issues at a New Zealand academic institution. Int J Occup Environ Med. 2011;2 (3):166-171.

12. Nylenna M, Fagerbakk F, Kierulf P. Authorship: attitudes and practice among Norwegian researchers. BMC Med Ethics. 2014;15:53. doi:10.1186/1472-6939-15-53

13. Das KK, Vallabha T, Patil SM, Ray J, Deepak KK. Knowledge on ethical authorship: a comparative study between medical and pharmacy faculty. J Young Pharm. 2016;8(2):136-140. doi:10.5530/ jyp.2016.2.15

14. Karani R, Ognibene FP, Fallar R, Gliatto P. Medical students' experiences with authorship in biomedical research: a national survey. Acad Med. 2013;88(3):364-368. doi:10.1097/ACM.0b013e31827fc6ae

15. Flanagin A, Carey LA, Fontanarosa PB, et al. Prevalence of articles with honorary authors and ghost authors in peer-reviewed medical journals. JAMA. 1998;280(3):222-224. doi:10.1001/jama.280.3.222

16. Quan SF. Guests and ghosts begone-guest authorship and ghostwriting and the journal of clinical sleep medicine. J Clin Sleep Med. 2008;4(3):203.

17. Chimonas S, Evarts SD, Littlehale SK, Rothman DJ. Managing conflicts of interest in clinical care: the "Race to the Middle" at US Medical Schools. Acad Med. 2013;88(10):1464-1470. doi:10.1097/ ACM.0b013e3182a2e204 


\section{Publish your work in this journal}

Advances in Medical Education and Practice is an international, peerreviewed, open access journal that aims to present and publish research on Medical Education covering medical, dental, nursing and allied health care professional education. The journal covers undergraduate education, postgraduate training and continuing medical education including emerging trends and innovative models linking education, research, and health care services. The manuscript management system is completely online and includes a very quick and fair peer-review system. Visit http://www.dovepress.com/testimonials.php to read real quotes from published authors.

Submit your manuscript here: http://www.dovepress.com/advances-in-medical-education-and-practice-journal 